\title{
ESTRATÉGIAS DIDÁTICAS INOVADORAS NO ENSINO- APRENDIZAGEM ATRAVÉS DAS TIC'S NA ALFABETIZAÇÃO DE JOVENS E ADULTOS (EJA)
}

\author{
Rodrigo Andrade Dias ${ }^{1}$ \\ Javier Numan Caballero Merlo ${ }^{2}$
}

RESUMO: O presente estudo tem por objetivo analisar a Educação de Jovens e Adultos na rede municipal da cidade de Bom Jesus do Itabapoana - Rio de Janeiro. Considerando que a EJA exige reformulações pedagógicas e estruturais, discutimos o papel dos professores e da escola sobre as estratégias didáticas inovadoras para alfabetizar através de Tecnologia da Informação e Comunicação na escola da referida cidade. Para realização de tal pesquisa, tivemos um aparato de teóricos como: Maccafani (2017), Silva Junior (2019), Valente (2014) e em outros doutrinadores que defendem uma educação tecnológica na mesma linha abordada nessa investigação. A problemática fundamentou-se em analisar se a escola está preparada para propiciar uma educação em conformidade coma modernidade com intuito de fornecer uma aprendizagem significativa. Para tanto, com intenção de avaliar e obter resultados, utilizou-se uma abordagem qualitativa com enfoque descritivo, visto que esse tipo de pesquisa permite uma base interpretativa dos dados, sendo aplicada técnicas e instrumentos qualitativos que permitam responder aos objetivos e ao problema da investigação. Os participantes foram: a professora da EJA e a coordenadora da instituição. $O$ resultado final da pesquisa possibilitou constatar que a Educação de Jovens e Adultos na escola municipal Dr. Francisco Baptista de Oliveira em Bom Jesus do Itabapoana não possui estrutura física e pedagógica que atenda às necessidades dos educandos que a frequentam, sendo que os professores mostram-se inseguros em utilizar as tecnologias em sala de aula, pois não possuem formação que contemple tal temática.

Palavra-Chave: EJA. Ensino- Aprendizagem. Estratégia Didáticas.

ABSTRACT: This study aims to analyze the Education of Youth and Adults in the municipal network of the city of Bom Jesus do Itabapoana - Rio de Janeiro. Considering that EJA requires pedagogical and structural reformulations, we discuss the role of teachers and the school on innovative didactic strategies to teach literacy through Information Technology and Communication at the school in that city. To

\footnotetext{
${ }^{\mathrm{I}}$ Universidad Autónoma de Asunción - Paraguai.
}

${ }^{2}$ Universidad Autónoma de Asunción - Paraguai. 
carry out such research, we had an apparatus of theorists such as: Maccafani (2017), Silva Junior (2019), Valente (2014) and others scholars who defend a technological education along the same lines addressed in this investigation. The issue was based on analyzing whether the school is prepared to provide an education in accordance with modernity in order to provide a meaningful learning. For this purpose, with the intention of evaluating and obtaining results, we used a qualitative approach with a descriptive focus, as this type of research allows an interpretive basis for the data, applying qualitative techniques and instruments that allow to respond to the objectives and the research problem. The participants were: a professor at EJA and the coordinator of the institution. The final result of the research made it possible to note that the Education of Youth and Adults in the municipal school Dr. Francisco Baptista de Oliveira in Bom Jesus do Itabapoana does not have a physical and pedagogical structure that meets the needs of the students who attend it, and the teachers are insecure in using technologies in the classroom, as they do not have training that includes such thematic.

Keyword: EJA. Teaching-Learning. Didactic Strategy.

RESUMEN: Este estudio tiene como objetivo analizar la Educación de Jóvenes y Adultos en la red municipal de la ciudad de Bom Jesus do Itabapoana - Río de Janeiro. Considerando que EJA requiere reformulaciones pedagógicas y estructurales, discutimos el rol de los docentes y la escuela en estrategias didácticas innovadoras para enseñar alfabetización a través de las Tecnologías de la Información y la Comunicación en la escuela de esa ciudad. Para realizar dicha investigación, contamos con un aparato de teóricos como: Maccafani (2017), Silva Junior (2019), Valente (2014) y otros académicos que defienden una educación tecnológica en la misma línea abordada en esta investigación. El tema se basó en analizar si la escuela está preparada para brindar una educación acorde con la modernidad con el fin de brindar un aprendizaje significativo. Por ello, con la intención de evaluar y obtener resultados, se utilizó un enfoque cualitativo con enfoque descriptivo, ya que este tipo de investigación permite una base interpretativa de los datos, aplicando técnicas e instrumentos cualitativos que permitan dar respuesta a los objetivos y a la investigación. problema. Los participantes fueron: el docente de EJA y el coordinador de la institución. El resultado final de la investigación permitió constatar que la Educación de Jóvenes y Adultos en la escuela municipal Dr. Francisco Baptista de Oliveira en Bom Jesus do Itabapoana no cuenta con una estructura física y pedagógica que satisfaga las necesidades de los estudiantes que asisten. ello, y los docentes demuestran que si se sienten inseguros en el uso de tecnologías en el aula, ya que no cuentan con una formación que aborde este tema.

Palabra clave: EJA. Enseñanza-Aprendizaje. Estrategia didáctica. 


\section{INTRODUÇÃO}

Essa pesquisa aborda o Processo da Educação de Jovens e Adultos na escola municipal de Bom Jesus do Itabapoana, Rio de Janeiro, Brasil. Visto que é crescente os debates sobre essa temática, crescendo os desafios na escola que atende esse público em questão.

A necessidade de investigar o processo da EJA deu-se primeiramente pela facilidade em se obter uma escola para realizar a pesquisa junto a Secretaria Municipal de Educação de Bom Jesus do Itabapoana, onde esse pesquisador não se enquadra como professor, contudo obteve permissão para realizar a investigação. Assim, resultou uma abordagem temática como processo de análise e descoberta dos principais entraves e barreiras que dificultam os educandos e educadores que se faziam presentes na escola.

No Brasil existe legislação vigente que aborda a temática de jovens e adultos, em diferentes linhas cronológicas de tipos de governos, sendo uma justificativa para saber se as esferas governamentais estão subsidiando financeiramente a oferta de ensino, visto que, a EJA exige mudanças, sendo governamentais e educacionais.

Nessa perspectiva, aumenta-se o quantitativo de educandos na modalidade de jovens e adultos em uma época tecnológica, de grande facilidade de acesso. Baseado nessa ideologia, cabe descobrir se esses educandos estão sendo oportunizados com uma aprendizagem de qualidade adequada ao século vigente no que tange as práxis pedagógicas, conjecturando se os professores dispõem de formação que lhes possibilitem lecionar com qualidade.

A práxis docente evoluiu no decorrer dos séculos e, ao constatar períodos históricos, a educação desses jovens e adultos fora segregadas num segundo plano, visto que não oportunizaram os estudos na idade correta, numa história recente brasileira, segregados durante o regime militar. Os pesquisadores relatam professores não habilitados para gerir tal informação, bem como escolas incapazes fisicamente e pedagogicamente de atender esse público.

Diante tais informações e após inúmeras indagações a respeito do processo educacional na EJA, pode-se destacar: Houve avanços educacionais? O que é o programa EJA? É importante dispor ao educando EJA ensino com viés tecnológico? A 
estrutura física da escola contribui com a proposta de ensino? Quais situações interferem o processo de ensino-aprendizagem? Os professores necessitam de formação apropriada para atender jovens e adultos?

Nessa linha de raciocínio, acredita-se que tais problemáticas apresentam uma configuração específica quanto o que seria: as práxis dos tempos antigos até os dias atuais; o significado da EJA e sua relevância diante as TIC's; a preparação dos professores para atuação na EJA.

Mediante à relevância desse estudo, optou-se por realizar essa pesquisa por intermédio da análise da realidade educacional na Dr. Francisco Baptista de Oliveira em Bom jesus do Itabapoana utilizando várias fontes de informações com intuito de compreender e responder à pergunta dessa investigação, que é: Quais as principais estratégias didáticas no ensinoaprendizagempara alfabetização de jovens e adultos como uso dastecnologias da informação e comunicação no município de Bom Jesus do Itabapoana no Estado do Rio de Janeiro?

\section{OBJETIVO GERAL}

Como forma de responder à pergunta central dessa investigação, bem como responder aos questionamentos elencados acima, o objetivo geral dessa pesquisa é analisar as principais estratégias didáticas no ensino-aprendizagem para alfabetização de jovens e adultos com o uso das tecnologias da informação e comunicação no município de Bom jesus do Itabapoana no Estado do Rio de Janeiro.

\section{OBJETIVOS ESPECÍFICOS}

- Identificar as estratégias e ou projetos que são adotados pela escola na Educação de Jovens e Adultos como medida de alfabetização por TIC's.

- Analisar o grau de formação docente para manejar TIC's em sala de aula. Descrever as dificuldades que os professores encontram no dia a dia de sala de aula para a inovação da estratégia didática na educação de jovens e adultos.

- Verificar possíveis situações na escola que podem ser elencadas como causa de ineficiência escolar na educação de jovens e adultos numa visão docente. 


\section{METODOLOGIA}

A abordagem utilizada foi via qualitativa, que possibilitou analisar os fenômenos correspondentes ao processo educativo no que tange à EJA. A enfoque da pesquisa é descritivo, pois elencamos situações reais da escola em seu contexto educacional no município de Bom Jesus do Itabapoana. A pesquisa foi realizada em uma escola municipal da cidade de Bom Jesus do Itabapoana: Dr. Francisco Baptista de Oliveira, no qual participaram dessa investigação: uma professora e uma coordenadora.

Para analisar se o município de Bom Jesus do Itabapoana apresenta projetos educacionais, se existe formação apropriada para o público alvo EJA, foi elaborado uma entrevista aplicado a coordenadora e a professora da escola do município com perguntas abertas sobre como estão sendo abordadas as questões educacionais e da práxis educativa na escola municipal. Por intermédio de tal técnica, podemos certificar se existem propostas educacionais voltadas a EJA na escola.

Finalizando a aplicação das técnicas e instrumentos, recolhemos os dados e iniciamos a análise, agrupando-os em busca de uma temática comum, nomeando aos eixos e criando quatro categorias de análises, possibilitando conhecer a situação da EJA na escola investigada. Conclui-se que apesar dos avanços tecnológicos referentes a educação e a práxis educativa, ainda temos uma realidade distante do ideal, com os sistemas educacionais escolares desestruturados e atrasados.

\section{RESULTADOS}

Após análise e interpretação dos dados, obtivemos respostas satisfatórias ante os objetivos da pesquisa ora posta, bem como a pergunta problema norteadora da pesquisa. Ainda permitiu que obtivéssemos outras informações sobre o processo de ensino-aprendizagem na EJA na cidade de Bom jesus do Itabapoana que possibilitará como orientação para futuras melhorias na escola investigada, bem como base propícia para realização de outros estudos sobre essa temática.

Considerando tais aspectos, apontamos os desafios $e$ as dificuldades enfrentadas pela escola no que tange as práxis docentes inovadoras por intermédio das 
TIC's, o que possibilitou uma análise crítica sobre a situação do processo de ensinoaprendizagem EJA na escola base dessa pesquisa.

Os resultados encontrados pós-aplicação das técnicas e instrumentos condiz com os resultados, visto que o sistema de ensino da escola não está preparado para propiciar um ensino digital na escola. Podemos destacar que os resultados foram satisfatórios, como também possibilitam a necessidade de novos debates que favoreçam a inserção de estratégias didáticas por intermédio das TIC's.

Outro fator importante dessa investigação foi perceber que até a presente não foi dada importância a utilização de tecnologias no processo de ensino-aprendizagem, visto que a escola possui um a sala de informática trancada, pouco utilizada e sem expectativa de fluir um ensino didático tecnológico inovador.

Como anteriormente abordado no Marco Teórico, vários autores discorrem sobre as instalações das instituições quanto os materiais tecnológicos, onde as salas ficam trancadas como se fosse proibido uma aproximação.

De tal forma, conclui-se que o sistema de ensino para jovens e adultos na escola de Bom Jesus do Itabapoana necessita passar mudanças, tanto na parte estrutural quanto na parte pedagógica, visto que a escola possui instalações inadequados para atender as necessidades educacionais, bem como não possuem materiais pedagógicos tecnológicos que contribuam com o trabalho do professor.

A realização dessa investigação foi com o intuito de observar se os jovens e adultos estão recebendo uma educação condizente com a modernidade, sendo valorizadas o máximo de informações com os envolvidos nesse processo.

Em relação ao objetivo número or que foi analisar as estratégias didáticas e \ou projetos na escola por TIC como medida de alfabetização, percebemos um vasto conteúdo tecnológico que os docentes podem utilizar como estratégia para alfabetizar. Percebemos avanço no que tange às TIC's, contudo, esses avanços não condizem com a realidade encontrada na escola.

As conclusões referentes a esse objetivo basearam-se na observação do investigador e na aplicação da técnica de entrevista junto a professora e a coordenadora EJA do município. Os resultados obtidos foram satisfatórios, atingindo o objetivo da 
investigação e confirmando que as estratégias didáticas passam pelo crivo de cada educador, sem uma diretriz educacional para se basear em suas práxis educacional.

Assim, em relação ao objetivo 02 que foi descrever a formação docente para utilizar as TIC's, percebemos uma evolução histórica da profissão docente, desde a época grega, passando pelos momentos humanistas e renascentistas até o século XXI ao analisarmos as práxis docentes de cada época. Percebemos que houve avanço no que diz respeito as práticas pedagógicas, porém, esses avanços não correspondem com a realidade na escola investigada.

As conclusões referentes a esse objetivo basearam-se na observação do investigador e na aplicação da técnica de entrevista junto a professora e a coordenadora EJA do município. Os resultados obtidos foram satisfatoriamente suficientes para atingir esse objetivo e para confirmar que a formação docente é insuficiente para gerir TIC's na escola.

Os recursos encontrados na escola são precários, não condizentes com as necessidades dos educandos, tornando difícil o trabalho do educador, bem como dificulta o desenvolvimento dos alunos. Dessa forma, os resultados obtidos propiciaram dados para atingir o objetivo.

No que tange ao objetivo 03, que foi identificar as dificuldades encontradas pelos professores para utilização das TIC's no ensino-aprendizagem inovador, mais uma vez obtivemos êxito quanto aos objetivos da investigação. Nesse sentido, os dados confirmaram que os professores encontram dificuldades para utilizar as TIC's, visto a falta de preparo na formação para lidar com as TIC's.

Nessa seara, as conclusões foram de que os professores necessitam estar mais bem qualificados para prover uma educação de qualidade por intermédio das TIC's, sendo que por intermédio de uma formação continuada propiciaria condições para dirimir angústias e fortificar as motivações educacionais.

Em relação ao objetivo 04, que foi identificar situações nas escolas causadoras de ineficiência estratégica na EJA, foram atingidos os objetivos da investigação. Nesse sentido, os dados confirmam que a causa de ineficiência passa pela não compreensão das TIC's como ferramenta didática por não possuir uma diretriz do MEC para tal. Contamos com a participação professora e da coordenadora. 
Portanto, em conformidade com os dados obtidos dos objetivos específicos, reiteramos as conclusões de que o processo de ensino-aprendizagem na EJA na escola de Bom Jesus do Itabapoana necessita de alterações, investimentos e reformulações, tanto na área pedagógica quanto na estrutural. Tal investigação e, contando com a participação dos envolvidos, nos permitiu confirmar que o viés tecnológico no município não foi observado até a presente com a devida importância.

\section{CONSIDERAÇÕES FINAIS}

Por intermédio dos resultados atingidos com a realização da pesquisa, bem como em virtude de situações que necessitam de um maior apreço da escola quanto do poder público municipal, recomenda-se para estudos futuros que a Secretaria de Educação Municipal invista na capacitação dos profissionais da educação por intermédio da formação continuada ou por cursos oferecidos pela administração pública municipal, bem como invista no aparato tecnológico das escolas, adaptando-as a realidade do século XXI para que os alunos e professores desfrutem de um espaço que atenda as expectativas.

Ainda poderemos recomendar uma divisão por faixa etária na turma da EJA, oferecendo um atendimento mais individualizado, bem como propiciando uma maior utilização os recursos multimídias e a sala de informática, onde com o auxílio de profissionais capacitados, poderiam atender os alunos EJA e oferecer-lhes oportunidades de aprendizado via recurso tecnológico. Por fim, podemos sugerir que a escola crie projetos lúdicos digitais, de modo a favorecer o aprendizado via TIC.

\section{REFERÊNCIAS BIBLIOGRÁFICAS}

Abbagnano, N. \& Visalberghi, A. (198I) Tradução de Glicínia Quartin. História da pedagogia (Vol. I). Lisboa: Livros Horizonte.

Alves, L., Guimarães, H., Oliveira G. \& Rettori, A. (2004) Ensino On-Line, jogos eletrônicos e RPG: Construindo novas lógicas. In: Conferência eLES 'o4, Aveiro-Pt, 2004, Bahia. Anais... Bahia: Universidade do Estado da Bahia. Disponível em: www.comunidadesvirtuais.pro.br/ead/artigo.pdf Acesso em: 22 mai. 2019. 
Amparo, M. \& Furlanetti, M. (20II) Inclusão Digital na Educação de Jovens e Adultos: dificuldades e desafios. In: Congresso Nacional de Educação, 3, 20II, Ponta Grossa PR. Anais... Ponta Grossa: ISAPG. Disponível em: www2.fct.unesp.br Acesso em: 20 mai. 2019.

Aranha, M. L. de A. (2006) História da educação e da pedagogia - Geral e Brasil. 3. ed. São Paulo: Moderna.

Barbosa, E. \& Moura, D. (2013) Metodologias ativas de aprendizagem na Educação Profissional e Tecnológica (Vol. 39). B. Tec. Senac, Rio de Janeiro. Disponível em: www.bts.senac.br/index.php/bts/article/view/349 Acesso em: 22 mai. 2019.

Berbel, N. A. N. (20II) As metodologias ativas e a promoção da autonomia dos estudantes (Vol. 32). Semina: Ciências Sociais e Humanas, Londrina. Disponível em: www.uel.br/revistas/uel/index.php/seminasoc/article/view/ro326/ro999 Acesso em: 22 mai. 2019.

Bévort, E. \& Belloni, M. L. (2009) Mídia-educação: conceitos, histórias e perspectivas (Vol. 30). Educação \& sociedade: Campinas.

Bom Jesus do Itabapoana. Secretaria Municipal de Educação. Disponível em: www.bomjesus.rj.gov.br Acesso em: 07 ago. 2019.

Brasil. Constituição da República Federal do Brasil. Brasília, DF: Senado Federal, 1988. $292 \mathrm{p}$.

Brasil. Lei no 9.394, de 20 de dezembro de 1996. Estabelece as diretrizes e bases da educação nacional. Acesso em: 20 mai. 2019.

Brasil. Resolução CNE/CEB no 1 , de 5 de julho de 2000. Estabelece as Diretrizes Curriculares Nacionais para a Educação e Jovens e Adultos. Acesso em: 20 jun. 2019.

Brasil. Decreto no 5.154 de 23 de julho de 2004. Regulamenta o $\$ 2^{\circ}$ do art. 36 e os arts. 39 a 4I da Lei no 9.394, de 20 de dezembro de 1996, que estabelece as diretrizes e bases da educação nacional, e dá outras providências. Acesso em: 20 jun. 2019.

Brasil. Decreto no 5.840, de 13 de julho de 2006. Institui, no âmbito federal, o Programa Nacional de Integração da Educação Profissional com a Educação Básica na Modalidade de Educação de Jovens e Adultos - PROEJA, e dá outras providências. Acesso em: 20 jun. 2019. 
Brasil. Ministério da Educação. Secretaria de Educação Básica. Secretaria de Educação Continuada, Alfabetização, Diversidade e Inclusão. Secretaria de Educação Profissional e Tecnológica. Conselho Nacional da Educação. Câmara Nacional de Educação Básica. Brasília: MEC, SEB, DICEI, 2013. Acesso em: 20 jun. 2019.

Cambi, F (1999). História da pedagogia. São Paulo: Unesp.

Campoy, T. (2016) Metodología de la investigación científica. Ciudad del Este (py) U.N.C. del Este.

Chauí, M. (2002). Introdução à história da filosofia. São Paulo: Cia. das letras.

Christensen, C., Horn, M. \& Staker, H. (2013) Ensino Híbrido: uma Inovação Disruptiva? Uma introdução à teoria dos híbridos. Disponível em: www.provir.org/wpcontent/uploads/2014/o8/PT_Is-K-I2-blended-learningdisruptive-Final.pdf Acesso em: 20 jun. 2019.

Correa, D. S. P. \& Scherer, S. (2012) Uso de TIC nas práticas de acadêmicos de um curso de licenciatura em matemática na modalidade EAD (Vol. I). In: XI Encontro Sul-matogrossense de Educação Matemática. Nova Andradina.

D’Ambrósio, U. (1997). Educação Matemática - da teoria a prática. 2. ed., CampinasSP: Papirus.

De Barrenechea, M.A. (2014). Filosofia e educação. Brasil. Unirio.

De Freitas, H.M.S. (2014). Filosofia e educação. Brasil. Unirio.

Di Pierro, M. C. (2005) Notas Sobre a Redefinição da Identidade e das Políticas Públicas da Educação de Jovens e Adultos no Brasil. Educ. Soc. (Vol. 26), Campinas. Di Pierro, M. C., Joia, O. \& Ribeiro, V. M. (200I) Visão da Educação de Jovens e Adultos no Brasil (Vol. 2I). Cadernos Cedes, Campinas - SP.

Figueiredo, R, Zambom, A. C. \& Saito, J. (20oI) A Introdução da Simulação como Ferramenta de Ensino e Aprendizagem. Disponível em: www.abepro.org.br/biblioteca/ENEGEP200I_TRIII_0822.pdf Acesso em: 22 jun. 2019. Gemignani, E. (2012) Formação de Professores e Metodologias Ativas de EnsinoAprendizagem: Ensinar Para a Compreensão (Vol. I). Revista Fronteira da Educação [online], Recife. Disponível em: www.forteirasdaeducacao.org/index.php/fronteiras/article/view/I4 Acesso em: 22 jun. 2019 
Gil, A. C. (2008). Métodos e técnicas de pesquisa social. Atlas.

Jaeger, W. (200I). Paidéia. São Paulo: Martins Fontes.

Jucá, S. (2006) A Relevância do uso de softwares educativos na educação profissional (Vol. 8). Revista Ciência e Cognição. Acesso em: 22 jun. 2019.

Lakatos, E. M., \& Marconi, M. D. A. (2003). Fundamentos da metodologia científica. In Fundamentos da metodologia científica. Altas.

Lakatos, E. M., \& Marconi, M. D. A. (2010). Metodologia Científica. 6. Ed. - 4. Reimpr. São Paulo: Atlas.

Larroyo, F. (1982) História geral da pedagogia. Tomo I. Tradução de Luiz Aparecido Caruso. São Paulo: Mestre Jou.

Luzuriaga, L. (1984) História da educação e da pedagogia. (Vol. 59). Tradução e notas de Luiz Damasco Penna e J. B. Damasco Penna. is ed. São Paulo: Companhia Editora Nacional.

Maccafani, A. P. da S. (2017) Tecnologias digitais e metodologias ativas aplicadas à educação profissional e EJA. Londrina: Editora e Distribuidora Educacional S.A.

Manacorda, M. A. (200o) História da educação da Antiguidade aos nossos dias. 8. ed.

Tradução de Gaetano Lo Monaco. São Paulo: Cortez.

Menegazze, T \& Araújo, F. (20II) O Uso de Blogs na Educação de Jovens e Adultos.

Disponível

em: www.repositorio.ufsm.br/bitstream/handle/r/2859/Menegazzi_Tania_Maria_Moura _Dutra.pdf Acesso em: 20 jul. 2019.

Minayo, de S. M. C. (200I). Pesquisa social: teoria, método e criatividade. Editora Vozes Limitada.

Monroe, P. (1988) História da educação. Tradução de Idel Becker. São Paulo: Companhia Editora Nacional.

Moran, J. (2015) Mudando a Educação com Metodologias Ativas (Vol. 2). In: Souza, C. A. de;Morales, O. E. T. Convergências Midiáticas, Educação e Cidadania: aproximações jovens. Disponível em: www2.eca.usp.br/moran/wpcontent/uploads/2013/12/mudando_moran.pdf Acesso em: 20 jul. 2019. 
Ribeiro, J. C. \&Falcão, T. (2009) Mundos virtuais e identidade social: processos de formação e mediação através da lógica do jogo. Tecnologias de Comunicação e Subjetividade.

Ribeiro, V. M. (1999) A formação de educadores e a constituição da educação de jovens e adultos como campo pedagógico (Vol. 20). Educação \& Sociedade. Disponível em: www.scielo.br/scielo.phpटipid=So13301999000300oro\&script $=$ sci_abstract\&tlng $=\quad$ pt Acesso em: 20 jul. 2019.

Sampaio, J. \& Leite, N. (2013). Performance indicators in game sports. In Routledge handbook of sports performance analysis. Routledge.

Santos, E. (2002) Formação de professores e cibercultura: novas práticas curriculares na educação presencial e a distância (Vol. II). Revista da FAEEBA - Educação e Contemporaneidade.

Savater, F. (2005) Ética para meu filho. Tradução de Monica Stahel. São Paulo: Planeta do Brasil.

Silva Junior, V. M. da. (2019) Letramento Digital: o uso das mídias digitais no ensino de Língua Portuguesa na EJA. Salvador.

The Belmont Report. (Julho de 2000). Considerações Éticas. Acesso em: I9 de ago de 2019, de http://www.hhs.gov/ohrp/humansubjects/guidance/belmont.htm Triviños, A. N.S. (2006). Introdução à pesquisa em ciências sociais: a pesquisa qualitativa em educação. São Paulo: Atlas.

Valente, J. A. (2014) Blended learning e as mudanças no ensino superior: a proposta da sala de aula invertida. [online]. Educar em Revista. Universidade Federal do Paraná. Disponível em: www.scielo.br/pdf/er/nspe4/oror4358-er-esp-o4-ooo79.pdf Acesso em: 20 jul. 2019.

Vaz, H.C. de L. (200o) Antropologia filosófica I. 5 ed. São Paulo: Loyola. 